\section{Case study of a new method for the classification and analysis of Dryocosmus kuriphilus Yasumatsu damage to young chestnut sprouts}

\author{
Alberto Maltoni, Barbara Mariotti, Andrea Tani
}

Dryocosmus kuriphilus is a new chestnut pest that is causing a serious problem worldwide. This gall wasp causes severe infestations of Italian Castanea sativa stands, which lowers their productivity. The most effective method for controlling gall wasp infestations is to introduce the parasitoid, Torymus sinensis, although experience shows that it can be 6-18 years before it is effective in reducing the infestation to acceptable levels. From a silvicultural point of view, it is important to reduce the damage as rapidly as possible to maintain plant vigour and fruit production, thereby avoiding chestnut stand degradation and abandonment before biological control is effective. This study analyzed the damage caused by Dryocosmus kuriphilus during normal plant development and detected differences in plant susceptibility, irrespective of genetic factors. Data were collected from a young Castanea sativa coppice stand in Tuscany (Italy) where damage was evaluated during the 2010 growing season. The study consisted of two phases: (1) classification of the damages caused by galls; and (2) studying the galls and damage distribution effects on different vigour chestnut sprouts to determine whether there were preferred oviposition sites or different degrees of susceptibility to gall wasp attack depending on a plant's physiological state. The $D$. kuriphilus damage classification scale was based on two factors: damage position (the vegetative organ attacked) and damage effect (abnormal organ development caused by galls). This classification included damage types that had not been previously described in literature. The statistical analysis identified differences in damage susceptibility in terms of: axis (stem or branches), plant organs (shoots, leaves, or buds), position of the attacked node (high or low region of the axis), and sprout vigour. Information on the $D$. kuriphilus damage distribution and its effect on plants with different levels vigour can be used to develop suitable cultural practices that could reduce the negative impact of this insect on fruit and wood production.

Keywords: Castanea sativa, Chestnut gall wasp, Damage distribution, Damage susceptibility, Vegetative vigour

\section{Introduction}

The chestnut gall wasp (Dryocosmus kuriphilus Yasumatsu; Hymenoptera: Cynipi$d a e)$ is a serious pest that attacks species belonging to the genus Castanea (Aebi et al. 2007, Abe et al. 2007, Quacchia et al. 2008). It was accidentally introduced into northern Italy during 2002 and it has spread to most Italian Castanea sativa stands (Graziosi \& Santi 2008), where it adversely affects their productivity in terms of fruit and timber (Kato \& Hijii 1997, Bosio et al. 2010, Turchetti et al. 2010). This wasp has reached European chestnut stands in France, Switzerland, Slovenia, and Hungary more recently (EPPO 2006, 2007, 2008, Quacchia et al. 2008, Forster et al. 2009, EFSA 2010), and an EFSA report stated that D. kuriphilus has very high potential for establishment in the
EU wherever the climate is suitable for Castanea sativa growth (i.e., southern, central, and western Europe - EFSA 2010).

D. kuriphilus is a gall-inducing insect that causes significant damage to actively growing host plant organs, which prevents their normal development and reduces their photosynthetic activity (Kato \& Hijii 1997, Cooper \& Rieske 2007, Cooper \& Rieske 2009). The effects include a progressive decrease in tree vigour and branch and tree mortality when severe infestations of young plantlets or weak plants occur (Payne et al. 1975, Anagnotakis \& Payne 1993, Kato \& Hijii 1997, Cooper \& Rieske 2007). A recent survey has highlighted blight damage recurrence in gall wasp-infected stands (Turchetti et al. 2010), suggesting that the insect reduced plant vigour and enhances blight $\square$ Dipartimento di Economia, Ingegneria, Scienze e Tecnologie Agrarie e Forestali (DEISTAF), Università degli Studi di Firenze, v. San Bonaventura 13, I-50145 Firenze (Italy)

(a) Alberto Maltoni

(alberto.maltoni@unifi.it)

Received: May 20, 2011 - Accepted: Mar 07, 2012

Citation: Maltoni A, Mariotti B, Tani A, 2012. Case study of a new method for the classification and analysis of Dryocosmus kuriphilus Yasumatsu damage to young chestnut sprouts. iForest 5: 50-59 [online 2012-04-30] URL: http://www.

sisef.it/iforest/contents/?id=ifor0598-008

Communicated by: Alberto Santini

\section{fungus activity.}

Tests detecting resistant $C$. sativa cultivars were successful for about 20 years in Japan (Kajiura \& Machida 1961); afterwards formerly resistant cultivars were attacked by a novel virulent strain of the insect (Shimura 1972, Murakami 1981). Tests with Italian cultivars are not yielding encouraging results (Botta et al. 2005, Sartor et al. 2009). Thus the most effective method for controlling gall wasp infestation is to introduce one of its parasitoids, i.e., Torymus sinensis Kamijo (Hymenoptera: Torimidae - Moriya et al. 1989, 2002, 2004, Aebi et al. 2007). A promising method for dispersing Torymus sinensis throughout attacked Italian stands was developed by Torino University researchers and it has been adopted by the interested Italian Regional Forest Administrations (Alma et al. 2004, Aebi et al. 2007, MiPAF 2010a, 2010b, 2010c, 2010d). However, previous experience shows that it will be $6-18$ years before this approach is effective in reducing damage to acceptable levels (Moriya et al. 1989, Murakami et al. 2001). Productivity losses over that number of years could lead to severe reductions in human activity based in chestnut orchard stands.

From a silvicultural viewpoint, it is essential to rapidly reduce gall wasp infestation effects in chestnut plants by improving vigour and ensuring fruit production. This will prevent chestnut stand degradation and abandonment during the long delay period before the parasitoid is effective (Mariotti et al. 2009, Maltoni et al. 2010, Tani et al. 2010).

The aim of this study was to analyze the damage caused by Dryocosmus kuriphilus to normal plant development and to identify differences in plant susceptibility, regardless of genetic factors. Information on D. kuriphilus damage distribution and plant susceptibility to the attack could be used to de- 
Tab. 1 - List of the acronyms and their meaning. $\left({ }^{*}\right)$ : see text and Tab. 2 for explanations.

\begin{tabular}{|c|c|c|}
\hline Kind & Parameter & Meaning \\
\hline \multirow[t]{2}{*}{ Sprouts } & $V$ & Vigorous sprouts \\
\hline & $N V$ & Non vigorous sprouts \\
\hline \multirow[t]{3}{*}{ Examined plant axes } & $A 1$ & Stem axis elongated in 2009 \\
\hline & $A 2$ & Stem axis elongated in 2008 \\
\hline & $B R$ & Branches developed in 2009 \\
\hline \multirow[t]{2}{*}{ Axis portion } & Lo & Low (basal) axis portion \\
\hline & $\mathrm{Hi}$ & High (apical) axis portion \\
\hline \multirow[t]{7}{*}{ Organs } & $S$ & Growing shoot \\
\hline & $L$ & Leaf \\
\hline & $L L$ & Leaf lamina \\
\hline & $L S t$ & Leaf stipule \\
\hline & $r B$ & Regular not flushing bud \\
\hline & $d B$ & Dormant bud \\
\hline & $a B$ & Absent bud \\
\hline \multirow{9}{*}{$\begin{array}{l}\text { Morphometric } \\
\text { parameters }\end{array}$} & A1l & A1 length \\
\hline & $A 2 l$ & A2 length \\
\hline & $\mathrm{Nn}$ & number of Nodes \\
\hline & $B R n$ & number of Branches per sprout \\
\hline & $m B R l$ & Branches mean length per sprout \\
\hline & $\Sigma B R l$ & Brl summation per sprout \\
\hline & $S n$ & number of Shoots per sprout \\
\hline & $S l$ & Shoots mean length per sprout \\
\hline & $\Sigma S l$ & Sl summation per sprout \\
\hline \multirow{18}{*}{$\begin{array}{l}\text { Phytosanitary state } \\
\text { and list of damages } \\
(*)\end{array}$} & $D$ & Damaged \\
\hline & $H$ & Healthy \\
\hline & $D S L$ & Damaged shoot, with galls only on leaves \\
\hline & $D S S$ & Damaged shoot, with deformed axis \\
\hline & $H L$ & Healthy leaf \\
\hline & $H S$ & Healthy shoot \\
\hline & $D L$ & Damaged leaf \\
\hline & $D S$ & Damaged shoot \\
\hline & $L L O$ & Damage on leaves \\
\hline & LL1 & \\
\hline & LL2 & \\
\hline & SLO & Damage on shoots, with galls only on leaves \\
\hline & SL1 & \\
\hline & SL2 & \\
\hline & SO & Damage on shoots, with galls on the axis \\
\hline & S1 & \\
\hline & $S 2$ & \\
\hline & $d B 2$ & Damage on dormant buds \\
\hline
\end{tabular}

velop suitable practices for reducing the negative impact of the insect on fruit and wood production.

Preliminary field observations have demonstrated that previous gall damage classifications (Kato \& Hijii 1997, Cooper \& Rieske 2009, Sartor et al. 2009) do not match the infestation characteristics in relation to the purpose of this work.

\section{Materials and methods}

Data were collected from young Castanea sativa sprouts to assess damage that occurred during the 2010 growing season. The study consisted of two phases. During the first phase, we classified the damage caused by galls, where the classification method measured the damage to the attacked organs and the consequences of the attack in terms of plant development and functionality. The tion was $650 \mathrm{~m}$ a.s.l. and it was west facing. The climate is sub-oceanic Mediterranean with a high average annual rainfall that is well distributed throughout all the seasons, except for a very short dry season in summer, which occurs irregularly during different years and throughout the region. Weather data were collected from two Regional Hydrologic Service monitoring stations, i.e., Castelpoggio ( $44^{\circ} 06^{\prime} 53^{\prime \prime} \mathrm{N}, 10^{\circ} 04^{\prime} 28^{\prime \prime}$ E), which is $1.5 \mathrm{~km}$ far from the site and at a similar elevation (525 $\mathrm{m}$ a.s.1.) and Carrara $\left(44^{\circ} 04^{\prime} 43^{\prime \prime} \mathrm{N}, 10^{\circ} 05^{\prime} 49^{\prime \prime} \mathrm{E}\right)$, which is approximately $8.5 \mathrm{~km}$ west of the study site but far less elevated (96 m a.s.1.) and near the Tyrrhenian Sea coast. Castelpoggio data are available only for rainfall and for a few years. In Carrara, the mean annual temperature is $13.7^{\circ} \mathrm{C}$, while the average maximum is $17.8{ }^{\circ} \mathrm{C}$ and the minimum is $10.4{ }^{\circ} \mathrm{C}$. In Carrara, the total annual precipitation is $1321 \mathrm{~mm}$, while in Castelpoggio it was 1818 $\mathrm{mm}$. The geological structure is formed of metamorphic rocks (marbles, schists, and quartzites), limestone, marls, and sandstones. The soils are Typic Dystrudepts loamyskeletal, mixed, and mesic (Regione Toscana 2002).

The study area $\left(44^{\circ} 07^{\prime} 033^{\prime \prime} \mathrm{N}, 10^{\circ} 04^{\prime} 58^{\prime \prime}\right.$ E) extended to about $2000 \mathrm{~m}^{2}$ and it was managed by the local government administration, who had earmarked it for research purposes since 1998. Six years ago the experimental site was burned in a fire, which acted as a clear cut. During the summer of 2010 , the experimental stand contained a

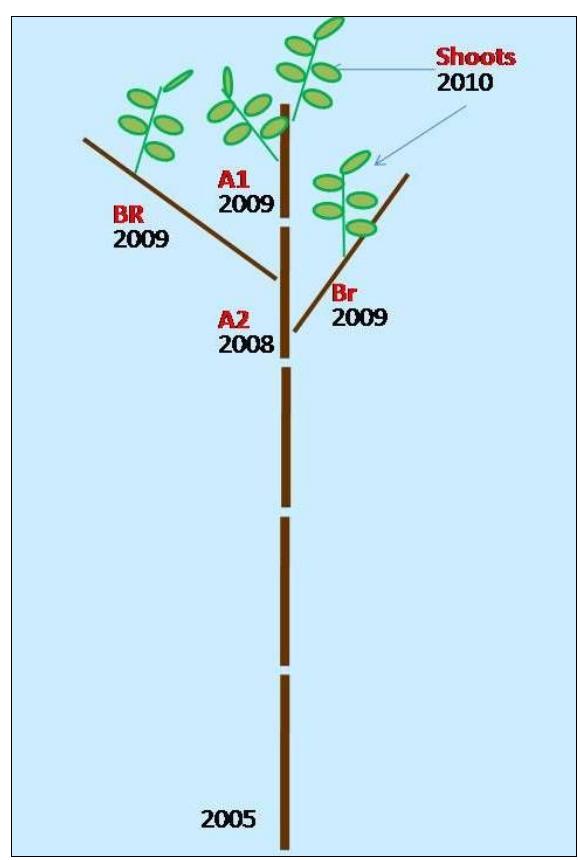

Fig. 1 - Sprout axes scheme considered for damage assessment in this study. $(A 1)$ : stem axis elongated in 2009; (A2): stem axis elongated in 2008; $(B R)$ branches developed in 2009 on $A 2$. 


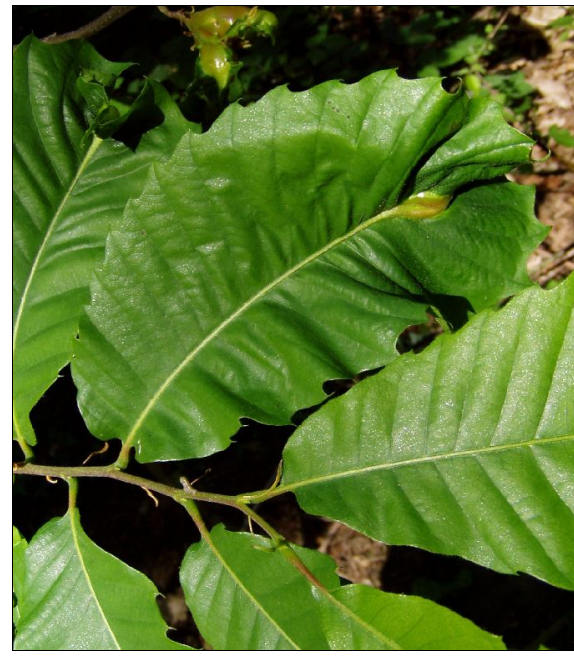

Fig. 2 - Leaf damage classified as $L L O$.

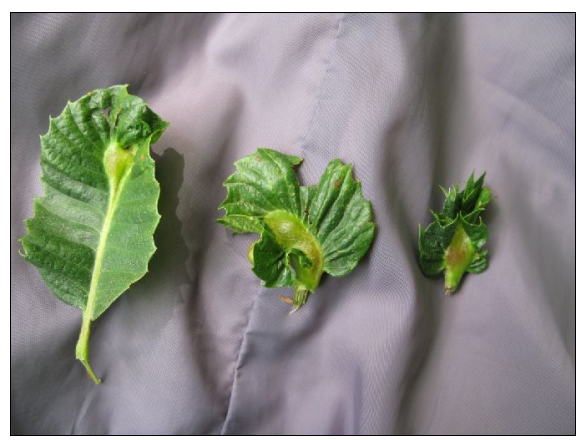

Fig. 3 - Leaf damages classified as $L L 1$ (left) and as $L L 2$ (middle and right).

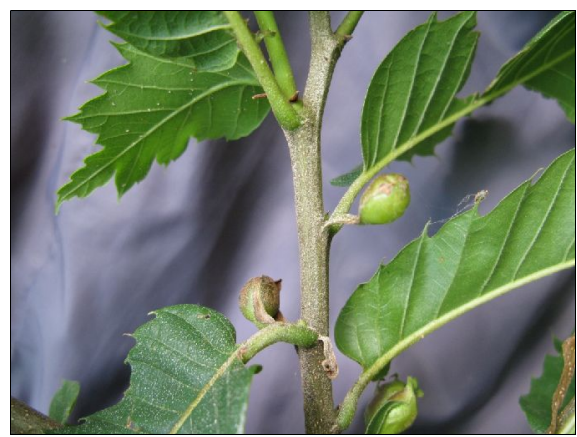

Fig. 4 - Leaf damage classified as LStO.

five-year-old pure chestnut coppice.

The gall wasp was first found at Castelpoggio in Tuscany during 2008. By the summer of 2010, the incidence of Dryocosmus kuriphilus was $100 \%$ in the study area. All plants were attacked severely.

\section{Damage survey}

During the summer of 2010, 35 sprouts were analyzed and assigned to two classes according to their position within the stump, i.e., 15 dominant vigorous sprouts $(V)$ and
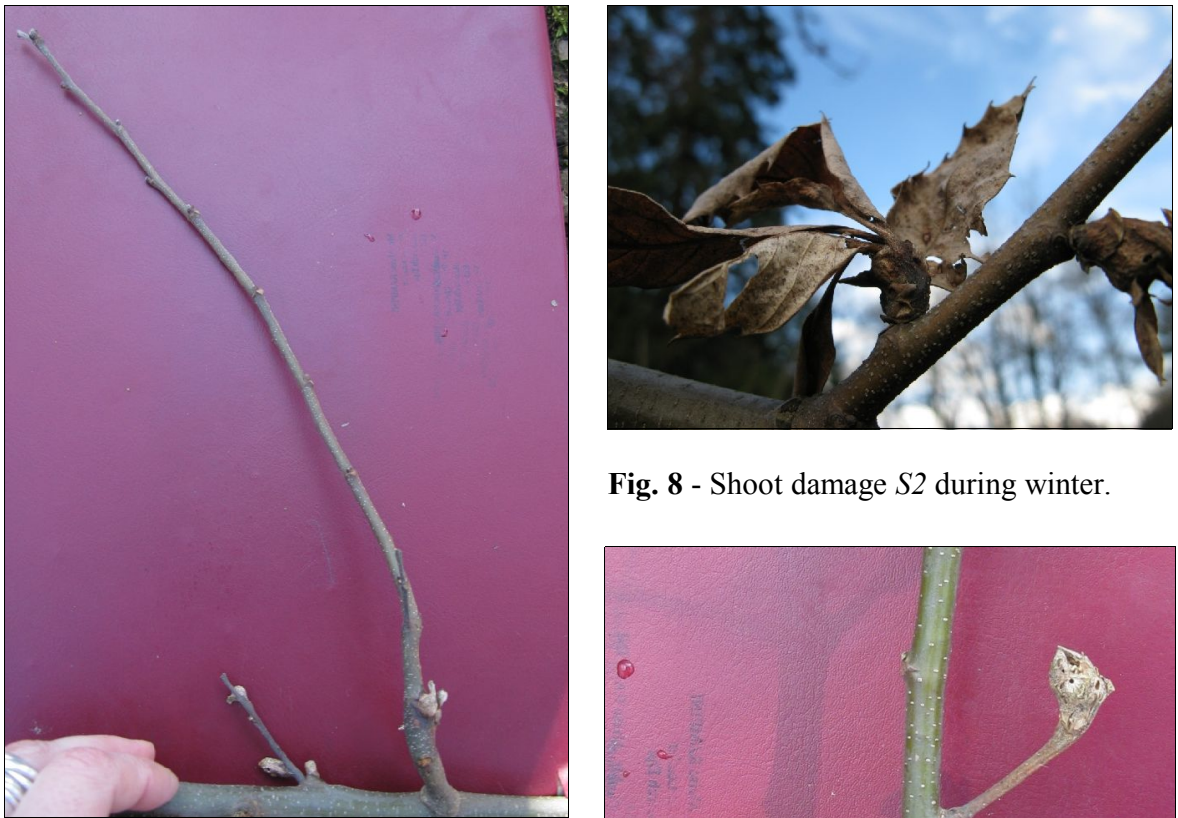

Fig. 8 - Shoot damage $S 2$ during winter.

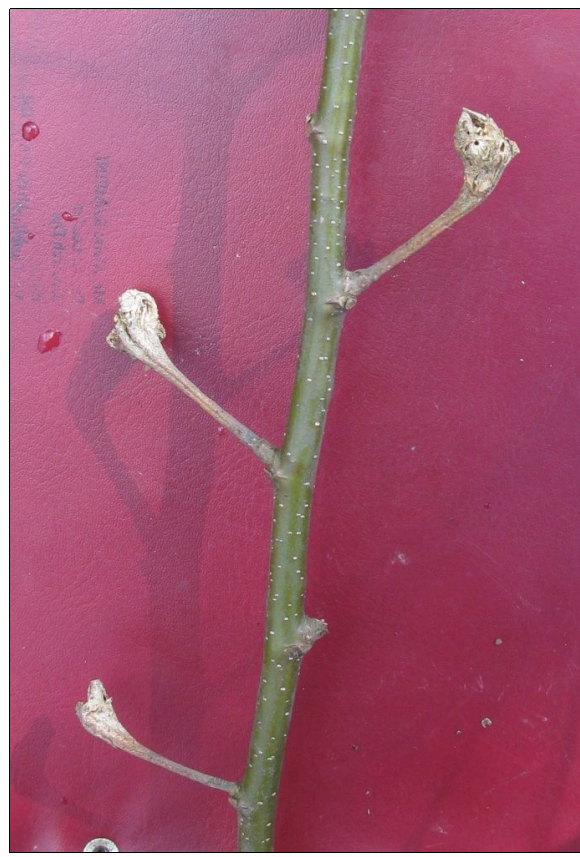

Fig. 6 - Shoot damage classified as $S 1$.

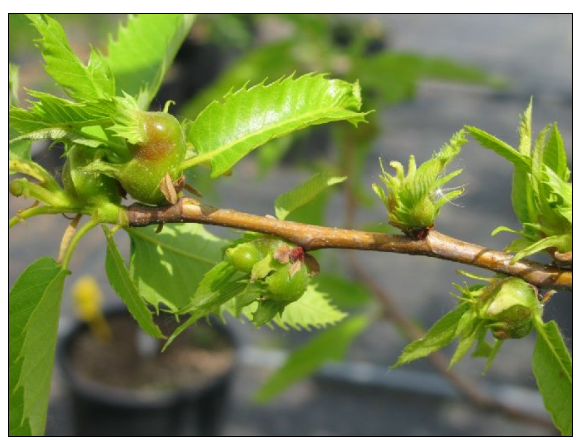

Fig. 7 - Shoot damage classified as $S 2$ during the growing season.

20 overtopped non-vigorous sprouts $(N V)$. Data were collected from the top portion of the plants by analyzing the stem axis that elongated in $2009(A 1)$, the stem axis that elongated in $2008(A 2)$, and the branches that developed in 2009 on $A 2(B R)$. The analyzed plant sections are summarized in Fig. 1. In terms of the D. kuriphilus damage eva-
Fig. 9 - Shoot damage $S 2$ during winter - the peduncled kind.

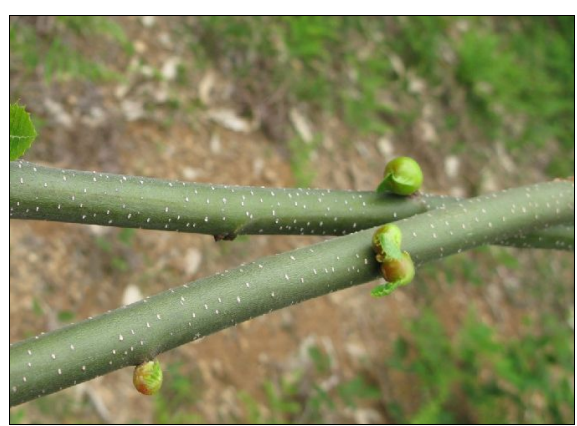

Fig. 10 - Dormant bud damage classified as $D B 2$.

luation, the survey focused on plant organs that developed during the growing season in 2010. Data was collected for every single node from the apex to the base of the $A 2$ axis along the stem and from the branch apex to their insertion, and a total of 3938 nodes 
Tab. 2 - The damages classification used in this study and description of classes.

\begin{tabular}{|c|c|c|}
\hline Organ & Class & Damages \\
\hline \multirow[t]{4}{*}{ Leaf } & LLO & The gall is located in the leaf central vein and the lamina has a quite normal extension (Fig. 2). \\
\hline & $L L 1$ & The gall is located in the leaf central vein and the lamina is deformed and only partially expanded (Fig. 3). \\
\hline & $L L 2$ & $\begin{array}{l}\text { The gall is located in the leaf central vein and the lamina is totally deformed (cockscomb shape) and very } \\
\text { highly reduced (Fig. } 3 \text { ). }\end{array}$ \\
\hline & LStO & The gall is in the stipule that is transformed in a little balloon; exit holes were recorded (Fig. 4). \\
\hline \multirow[t]{3}{*}{ Shoot } & So & $\begin{array}{l}\text { The gall (one or more) are located along the axis or on adjacent leaves and the axis development is nearly } \\
\text { normal. The galls on the axis don't cause any abrupt reduction in shoot diameter. Examining SO } 2009 \text { damage } \\
\text { data, it comes out that this kind of galls don't cause shoot death (Fig. 5). }\end{array}$ \\
\hline & S1 & $\begin{array}{l}\text { The gall (one or more) are located along the axis or on adjacent leaves; deviation of the axis direction and re- } \\
\text { duction of axis growth and diameter are evident. Usually this damage causes a photosynthetic activity area re- } \\
\text { duction during the current growing season and, regarding the collected data about S1 } 2009 \text { damages, causes } \\
\text { the shoot death in the following growing season (Fig. 6). }\end{array}$ \\
\hline & $S 2$ & $\begin{array}{l}\text { The galls (usually more than 1) cause a definitively abnormal shoot development (galls agglomerate similar to } \\
\text { a knob). The agglomerate can be peduncled. This damage compromises the photosynthetic activity area and, } \\
\text { regarding the collected data about } S 22009 \text { damages, causes the shoot death in the following growing season } \\
\text { (Fig. 7, Fig. 8, Fig. 9). }\end{array}$ \\
\hline Dormant Buds & $d B 2$ & $\begin{array}{l}\text { The gall causes a bud deformed development (balloon-shaped bud). This damage doesn't allow the develop- } \\
\text { ment of any future organ (Fig. 10). }\end{array}$ \\
\hline
\end{tabular}

were examined. Their position was labelled based on sequential numbering from the holding axis (stem $A 1, A 2$, or $B R$ ).

Each node was assigned to one of the following alternative cases:

- absence of bud or any vegetative organ $(a B)$;

- presence of a vegetative organ (growing shoot $S$ or leaf $L$ );

- presence of a latent bud that had not yet burst (normal sized, regular bud: $r B$; or smaller sized, dormant bud: $d B$ ).

The dormant buds $(d B)$ were distinguished as latent smaller buds, which were located in the basal portions of shoots or branches where their development was inhibited by plant stress (e.g., cuts or pathologies).

Due to their young age, stand inflorescences could not be considered in this study.

To evaluate the presence of Dryocosmus kuriphilus galls, we classified the organs as either damaged $(D)$ or healthy $(H)$. Thus, we recorded the position of the $H$ and $D$ organs, in terms of their node sequence along the $A 1$, $A 2$, and $B R$ axes. Galls were counted on the $D$ organs and any deformation caused by the galls was described. Damage that occurred on the $A 2$ stem axis during the 2009 growing season was still present (not yet abscissed), so it was also possible to evaluate these data.

\section{Damage classification}

The D. kuriphilus damage classification scheme proposed in this paper was based on two factors: damage position and damage effect. We considered the following:

- the vegetative organ attacked, i.e., POSITION;

- its abnormal development caused by galls, i.e., EFFECT.
Abnormal organ development leads to a reduction in the photosynthetic area, with different consequences depending on the organ attacked. Thus, we distinguished galls on stipules $(L S t)$, with no effect on the photosynthetic area, from galls on the leaf lamina $(L L)$. Foliar damage influences the current growing season (2010 in this study) directly and immediately, while shoot damage, in addition to the current season's growth, can also reduce the photosynthetic area in terms of leaf number in subsequent seasons.

The number of damage classification types was minimized to ensure that the classification scheme was as simple and functional as possible, which simplified our analysis of the damage distribution and plant susceptibility.

Each damage type was named with a letters related to the vegetative organ attacked $(d B$, $S, L L, L S t)$ with numbers specifying the degree of damage in terms of organ deformation (from 0 to 2 with an increasing scale of deformation). Observations of the 2009 galls on $A 2$ were also considered to refine the type definitions.

Damage types are briefly described and specific pictures were taken (Fig. 2 to Fig. $10)$.

\section{Plant Susceptibility to Dryocosmus kuri- philus}

Susceptibility to gall wasp attack was studied by collecting data from galls in the 2010 growing season.

The damage distribution was evaluated based on the presence of healthy or damaged organs $(L L, L S t, S$, and $d B)$ in the three axes $(A 1, A 2$, and $B R)$. The $\chi^{2}$ test was used to evaluate any differences in their occurrence. Plant susceptibility was studied by compa- ring the vigour of the different sprout classes. Before analyzing the damages, the $A 1, A 2$, and $B R$ growth parameters were measured to determine the characteristics of the two sprout vigour classes. A one-way ANOVA was performed to detect any differences in development and growth among the classes. The following variables were analyzed:

- Stem: $A 1$ length $(A 1 l), A 2$ length $(A 2 l)$

- Branches: number per sprout $(B R n)$, mean length per sprout $(m B R l)$, length summation per sprout $(B R n \times B R l=\Sigma B R l)$

- Nodes: number per sprout $(\mathrm{Nn}), A 1$ number of nodes per sprout $(A 1 N n)$, number of nodes per sprout on the branches $(B R n)$

- Shoots: number per sprout $(S n)$, mean length per sprout $(S l)$, length summation per sprout $(S n \times S l=\Sigma S l)$

Susceptibility was evaluated by considering the axes as a whole $(A 1+A 2+B R)$ and by separating $A 1, A 2$, and $B R$. The $\chi^{2}$ test was used to compare the vigour classes. The same analysis was performed for the damage of sprouts while separating the damage to shoots, leaves, and dormant buds.

The susceptibility was evaluated by dividing each axis $(A 1, A 2$ and $B R)$ into two regions. The axis nodes were halved to distinguish the apical (high, $H i$ ) and basal (lower, Lo) regions, and branches with less then 10 nodes were not included. The statistical analysis using $\chi^{2}$ tests considered all the damage and separated the damage to different organs. This analysis also included all the organs together while separately processing only the shoots data. Thus, three types of shoots were taken into account, i.e., healthy shoots $(H S)$, shoots with hanging galls on the leaves $(D S L)$, and deformed shoots (DSS). 
The growth and damage status of plants were evaluated using the mean value per sprout of the length of $H S, D S L$, and $D S S$ for each node starting from the top to the low region of $A 1$ and the $B R$ axis, which were calculated separately for the vigour classes. For branches, the length value was calculated as the mean per sprout of the sum of all the shoots that had developed from each node position of all branches.

All statistical tests were carried out by the StatSoft Statistica $8{ }^{\circledR}$ software package.

\section{Results}

Tab. 2 shows the D. kuriphilus damage classification scheme, supported by images of the different types of damage (Fig. 2 to Fig. 10).

The damage incidence is shown in Tab. 3. Over $50 \%$ of the damage was observed on growing shoots $(S)$ and their frequency increased with the severity of the damage. Less deformed shoots $(S O)$ were rare. Galls on leaves comprised about $40 \%$ of the total damage. The less harmful leaf galls were generally more common, about two-thirds of leaf damage included $L S t O, L L O$, and $L L 1$ damage which did not affect lamina extension significantly. The most damaging leaf galls (LL2) comprised $14.5 \%$. There was a low level of damage to the dormant buds $(6.5 \%)$ and this data should not be neglected given that an attacked dormant bud will not be able to generate new shoots in subsequent growing seasons. Stipule and dormant bud damage have not been previously described in the literature, but together they accounted for one-fifth of all the damage $(19.2 \%)$.

Before describing the damage distribution in the different plant sections, the axes $(A 1$, $A 2$ and $B R$ ) were characterized based on the organs that developed from each single node (Tab. 4). During the 2010 growing season, over $50 \%$ of the nodes did not differentiate into photosynthetic organs (leaves and/or shoots), although dormant buds (18.4\%) represent potential photosynthetic organs in future seasons. On average, the nodes that generated shoots and leaves comprised $37.7 \%$ of the total per sprout. Comparing the three axes the highest value of $S$ and $L$ (45.7\%) was attributed to $A 1$ with the lowest to branches (34.3\%). Most of the open nodes developed shoots and very few generated single leaves. This is relevant to future opportunities of developing a higher number of new buds, thereby increasing photosynthetic activity levels and vigour.

Tab. 5 shows the composition of the axes in terms of healthy and attacked nodes according to the damage classification. This also helps us to understand the contribution of each axis to the plant state and vegetative development during the 2010 growing season. The axis with the highest mean number of healthy shoots was $A I(A I=15.3 \%$ vs.

Tab. 3 - Frequency of damage types for each organ in 2010 growing season.

\begin{tabular}{lcc}
\hline Organs & Damage Type & Frequency \\
\hline Leaves & LSt0 & 12.7 \\
& $L L O$ & 0.5 \\
& $L L 1$ & 11.5 \\
& LL2 & 14.5 \\
& $($ total & 39.3 \\
Shoots & $S 0$ & 2.9 \\
& $S 1$ & 20.9 \\
& $S 2$ & 30.4 \\
& $($ total $)$ & 54.2 \\
\hline Dormant buds & $d B 2$ & 6.5 \\
\hline
\end{tabular}

Tab. 4 - Mean number of nodes $(N n)$ and mean frequency per sprout of organs developed by $A 1, A 2$ and $B R$ axes (as described in Fig. 1).

\begin{tabular}{lrrrr}
\hline Variable & $\boldsymbol{A 1}$ & $\boldsymbol{A 2}$ & $\boldsymbol{B} \boldsymbol{R}$ & Total \\
\hline$N n$ & 20.5 & 19.7 & 63.9 & 104.1 \\
$S(\%)$ & 43.6 & 39.1 & 32.4 & 35.9 \\
$L(\%)$ & 2.1 & 1.3 & 1.9 & 1.8 \\
$R B(\%)$ & 14.3 & 6.1 & 14.9 & 13.1 \\
$A B(\%)$ & 20.8 & 35.7 & 32.5 & 30.8 \\
$D B(\%)$ & 19.2 & 17.8 & 18.3 & 18.4 \\
\hline
\end{tabular}

$A 2=3.6 \%$ and $B R=6.9 \%$ ). Types of shoots damage with deformations ( $S 1$ and $S 2$ ) led to a decrease in new bud formation, which were much more frequent in $A 2$. Shoots that were able to develop future foliage $(H S+S O$ $+S L O+S L 1+S L 2)$ comprised $27.1 \%$ in $A 1,15.0 \%$ in $B R$, and $4.0 \%$ in $A 2$, while the overall average was $15.3 \%$.

The $\chi^{2}$ test indicated significant differences in the attack distribution on the three axes (Tab. 6). Differences were detected among all nodes and generated organs (leaves and shoots), whereas dormant bud damage was

homogeneous among the axes. The relative gall frequency increased from $A 1$ to $B R$ and $A 2$

Before describing the damage susceptibility according to the sprout vigour, we performed an ANOVA test to analyze the morphometric differences between the two vigour classes. This statistical test was useful to verify the class assignment because the more relevant aspects that were used to separate the sprouts into vigour classes were the social position in the stump and the size. Tab. 7 shows the ANOVA results. The vigo-

Tab. 5 - Phytosanitary state of the nodes: mean frequency (\%) per sprout of healthy ( $H S, H L$, $H d B)$ and damaged nodes grouped by organ and axis $(A 1, A 2$ and $B R)$.

\begin{tabular}{llcccc}
\hline Organ & Class & $\boldsymbol{A 1}$ & $\boldsymbol{A 2}$ & $\boldsymbol{B R}$ & Tot \\
\hline Shoots & $H S$ & 15.3 & 3.6 & 6.9 & 8 \\
& $S 0$ & 1.1 & 0.3 & 1 & 0.9 \\
& $S 1$ & 7.2 & 12.2 & 5.6 & 7.2 \\
& $S 2$ & 9.3 & 22.9 & 11.8 & 13.4 \\
& $L L 0$ & 0.3 & 0 & 0 & 0.1 \\
& $L L 1$ & 3.5 & 0 & 2.7 & 2.4 \\
& $L L 2$ & 5 & 0.1 & 3.1 & 2.9 \\
& $S t 0$ & 1.8 & 0 & 1.2 & 1.1 \\
& $H L$ & 1.8 & 0 & 0.9 & 0.9 \\
& $L L 0$ & 0 & 0 & 0 & 0 \\
& $L L 1$ & 0.1 & 0 & 0.3 & 0.2 \\
& $L L 2$ & 0.1 & 0.1 & 0.4 & 0.3 \\
& $S t 0$ & 0 & 1.2 & 0.3 & 0.4 \\
& $r B$ & 14.3 & 6.1 & 14.9 & 13.1 \\
& $a B$ & 20.8 & 35.7 & 32.5 & 30.8 \\
& $H d B$ & 17.5 & 16.2 & 16 & 16.3 \\
\hline
\end{tabular}


Tab. 6 - Differences of gall wasp susceptibility among the 3 axes $(A 1, A 2$ and $B R)$. Values are mean frequency per sprout of healthy $(\mathrm{H})$ and damaged (D) nodes. $a B$ and $r B$ were excluded from this analysis. $(* *)$ : $\mathrm{p}<0.01$; (ns): not significant.

\begin{tabular}{lccccccccr}
\hline \multirow{2}{*}{ Axis } & \multicolumn{2}{c}{ All the nodes } & \multicolumn{2}{c}{ Shoots } & \multicolumn{2}{c}{ Leaves } & \multicolumn{2}{c}{ Dormant Buds } \\
\cline { 2 - 9 } & $\boldsymbol{H}$ & $\boldsymbol{D}$ & $\boldsymbol{H S}$ & $\boldsymbol{D S}$ & $\boldsymbol{H} \boldsymbol{L}$ & $\boldsymbol{D L}$ & $\boldsymbol{H d B}$ & $\boldsymbol{D d B}$ \\
\hline$A 1$ & 53.4 & 46.6 & 35.1 & 64.9 & 86.7 & 13.3 & 91.3 & 8.7 \\
$A 2$ & 34.1 & 65.9 & 9.3 & 90.7 & 0 & 100 & 91.1 & 8.9 \\
$B R$ & 45.2 & 54.8 & 21.4 & 78.6 & 47.6 & 52.4 & 87.1 & 12.9 \\
$\chi^{2}$ & \multicolumn{2}{c}{$32.78^{* *}$} & \multicolumn{2}{c}{$56.82 * *$} & \multicolumn{2}{c}{$17.16^{* *}$} & \multicolumn{2}{c}{$2.69 \mathrm{~ns}$} \\
Total & 44.9 & 55.1 & 22.2 & 77.8 & 33.3 & 66.7 & \multicolumn{2}{c}{88.7} & 11.3 \\
\hline
\end{tabular}

Tab. 7 - Results of the one-way ANOVA carried out on morphological traits (see Tab. 1) for dominant, vigorous $(V)$ and overtopped non-vigorous sprouts $(N V)$. Mean values per sprout are displayed. $(* *): \mathrm{p}<0.01$.

\begin{tabular}{lrrr}
\hline \multicolumn{1}{c}{ Parameter } & NV & V & \multicolumn{1}{c}{ F } \\
\hline$A 1 l(\mathrm{~cm})$ & 41.3 & 79.2 & $42.74^{* *}$ \\
$A 2 l(\mathrm{~cm})$ & 71.1 & 139.2 & $42.54^{* *}$ \\
BRn & 4.4 & 8.6 & $151.20^{* *}$ \\
$B R l(\mathrm{~cm})$ & 19.6 & 30.5 & $16.12^{* *}$ \\
$\mathrm{Nn}$ & 76.4 & 170.7 & $54.25^{* *}$ \\
$S l(\mathrm{~cm})$ & 15.8 & 32.1 & $59.49^{* *}$ \\
$\mathrm{Sn}$ & 11.4 & 32.0 & $70.76^{* *}$ \\
$\Sigma S l(\mathrm{~cm})$ & 189.7 & 1014.2 & $120.10^{* *}$ \\
\hline
\end{tabular}

Tab. 8 - Axes attack susceptibility related to the plants vigour. $\chi^{2}$ test results (considering all the damaged organs together and distinguishing shoots, leaves and dormant buds damages). $(*): \mathrm{p}<0.05 ;(* *): \mathrm{p}<0.01 ;(\mathrm{ns})$ : not significant; (n/a): not applicable.

\begin{tabular}{|c|c|c|c|c|c|}
\hline Organs & Axes & Damage Class & NV & $\mathbf{V}$ & $\chi^{2}$ \\
\hline \multirow{8}{*}{$\begin{array}{l}\text { All damaged } \\
\text { nodes }\end{array}$} & \multirow[t]{2}{*}{$\mathrm{A} 1+\mathrm{A} 2+\mathrm{BR}$} & $\mathrm{H}$ & 56.9 & 37.9 & \multirow[t]{2}{*}{$69.66^{* *}$} \\
\hline & & $\mathrm{D}$ & 43.1 & 62.1 & \\
\hline & \multirow{2}{*}{$\mathrm{A} 1$} & $\mathrm{H}$ & 63.1 & 46.5 & \multirow{2}{*}{$12.55^{* *}$} \\
\hline & & $\mathrm{D}$ & 36.9 & 53.5 & \\
\hline & \multirow{2}{*}{$\mathrm{A} 2$} & $\mathrm{H}$ & 41.0 & 28.6 & \multirow{2}{*}{$6.82 * *$} \\
\hline & & $\mathrm{D}$ & 59.0 & 71.4 & \\
\hline & \multirow[t]{2}{*}{$\mathrm{BR}$} & $\mathrm{H}$ & 61.1 & 37.6 & \multirow[t]{2}{*}{$57.90 * *$} \\
\hline & & $\mathrm{D}$ & 38.9 & 62.4 & \\
\hline \multirow[t]{8}{*}{ Shoots } & \multirow[t]{2}{*}{$\mathrm{A} 1+\mathrm{A} 2+\mathrm{BR}$} & HS & 32.0 & 17.1 & \multirow[t]{2}{*}{$37.21 * *$} \\
\hline & & DS & 68.0 & 82.9 & \\
\hline & \multirow[t]{2}{*}{ A1 } & HS & 39.3 & 32.8 & \multirow[t]{2}{*}{$1.30 \mathrm{~ns}$} \\
\hline & & DS & 60.7 & 67.2 & \\
\hline & \multirow[t]{2}{*}{$\mathrm{A} 2$} & HS & 10.6 & 8.3 & \multirow[t]{2}{*}{$0.44 \mathrm{~ns}$} \\
\hline & & DS & 89.4 & 91.7 & \\
\hline & \multirow[t]{2}{*}{$\mathrm{BR}$} & HS & 39.3 & 13.7 & \multirow[t]{2}{*}{$59.19 * *$} \\
\hline & & DS & 60.7 & 86.3 & \\
\hline \multirow[t]{8}{*}{ Leaves } & \multirow[t]{2}{*}{$\mathrm{A} 1+\mathrm{A} 2+\mathrm{BR}$} & HL & 62.2 & 34.5 & \multirow[t]{2}{*}{$5.04^{*}$} \\
\hline & & DL & 37.8 & 65.5 & \\
\hline & \multirow[t]{2}{*}{ A1 } & HL & 100.0 & 50.0 & \multirow[t]{2}{*}{$\mathrm{n} / \mathrm{a}$} \\
\hline & & DL & 0.0 & 50.0 & \\
\hline & \multirow[t]{2}{*}{$\mathrm{A} 2$} & HL & 0.0 & 0.0 & \multirow[t]{2}{*}{$\mathrm{n} / \mathrm{a}$} \\
\hline & & DL & 100.0 & 100.0 & \\
\hline & \multirow[t]{2}{*}{$\mathrm{BR}$} & HL & 50.0 & 44.4 & \multirow[t]{2}{*}{$0.23 \mathrm{~ns}$} \\
\hline & & DL & 50.0 & 55.6 & \\
\hline \multirow[t]{8}{*}{ Dormant Buds } & \multirow[t]{2}{*}{$\mathrm{A} 1+\mathrm{A} 2+\mathrm{BR}$} & $\mathrm{HdB}$ & 96.4 & 83.3 & \multirow[t]{2}{*}{$27.63^{* *}$} \\
\hline & & DdB & 3.6 & 16.7 & \\
\hline & A1 & $\mathrm{HdB}$ & 94.4 & 87.9 & $1.93 \mathrm{~ns}$ \\
\hline & & DdB & 5.6 & 12.1 & \\
\hline & A2 & $\mathrm{HdB}$ & 96.8 & 85.0 & $5.35 * *$ \\
\hline & & DdB & 3.2 & 15.0 & \\
\hline & $\mathrm{BR}$ & $\mathrm{HdB}$ & 97.1 & 81.9 & $19.50 * *$ \\
\hline & & DdB & 2.9 & 18.1 & \\
\hline
\end{tabular}

rous sprout mean values were statistically higher for all variables, as follows: length of axes, branch number, and shoots length were about double $(A 1 l+91.8 \%, A 2 l+95.8 \%$, $B R n+95.5 \%$, and $S l+103.3 \%$ ) while the number of nodes and number of shoots were more than double $(N N+123.4 \%$; $S n$ $+180.5 \%)$. The vigor shoot length summation provided the most striking result $(\Sigma S l$ $+434 \%$ ), given that this variable was linked to crown growth and the development of photosynthetic organs.

The gall wasp attack susceptibility relationship to plant vigour was assessed for all shoot, leaf, and dormant bud nodes before separating them. The results of the axes susceptibility are shown in Tab. 8. For the axes as a whole $(A 1+A 2+B R)$, the vigorous sprouts had higher values and the $\chi^{2}$ test results demonstrated these differences, when considering all the organs and shoots, leaves, and dormant buds separately. Vigorous sprouts were more susceptible to attack when we evaluated all the damaged nodes on each axis. At a finer scale (for each organ type on $A 1, A 2$, or $B R$ ) the vigour classes did not differ in terms of shoot damage on $A 1$ and $A 2$ and, in terms of dormant bud damage, on $A 1$. Differences between the vigour classes were detected in the shoot damage on branches and dormant bud damage for $A 2$ and branches.

The vigorous and non-vigorous sprouts damage susceptibility was also evaluated considering the effect of the node position on the axis, i.e., high and low regions. The $\chi^{2}$ test results demonstrate the different susceptibility of vigour classes and different regions (Tab. 9). The high region tended to be attacked more than the low region. In the $A 1$ and $A 2$ upper regions, damage susceptibility was homogeneous among the vigour classes according to the $\chi^{2}$ test. Relative to the $A 1$ and $A 2$ high regions, the vigorous sprouts were attacked less than the non-vigorous sprouts. The overall higher vigorous sprout susceptibility shown in Tab. 8 was attributable to that found in the $B R$ portions and in the $A 1$ and $A 2$ low portion, where the frequency of attacked nodes was greatly and statistically higher.

Within the vigour classes, the influence of the node position along the axis (axis region) was statistically significant for the non-vigorous sprouts, whereas for the vigorous ones it was only significant in the branches.

The same analysis was conducted including the nodes with hanging shoots only (Tab. 10), which classified them into the following types: healthy shoots $(H S)$, shoots with hanging galls only on the leaves (DSL), and deformed shoots attacked along their axis $(D S S)$. The vigorous and non-vigorous sprouts susceptibility was different in the $A 1$ high and low regions, and in the top parts of branches. As a result of the regional divi- 
Tab. 9 - Damage susceptibility of high and low portions of the axes. For each axis $(A 1, A 2$, $B R$ ) mean values per sprout (\%) of healthy and damages nodes are reported. $\chi^{2}$ test results of the distribution of the healthy and damaged nodes between the vigour classes within the high or low axis portion and of the distribution of the healthy and damaged nodes between the high and low axis portion within the vigour classes. $\left(^{*}\right)$ : $\mathrm{p}<0.05 ;(* *): \mathrm{p}<0.01 ;(* * *)$ : $\mathrm{p}<0.001$; (ns): not significant.

\begin{tabular}{|c|c|c|c|c|}
\hline Parameters & Vigour (\%) & NV & $\mathbf{V}$ & $\chi^{2}$ test \\
\hline \multirow[t]{2}{*}{$\mathrm{Al} \mathrm{Hi}$} & $H$ & 40.4 & 43.8 & $0.29 \mathrm{~ns}$ \\
\hline & $D$ & 59.6 & 56.2 & \\
\hline \multirow[t]{3}{*}{ A1 Lo } & $H$ & 84.2 & 50 & $28.26 * *$ \\
\hline & $D$ & 15.8 & 50 & - \\
\hline & $\chi^{2}$ test & $39.99 * *$ & $1.04 \mathrm{~ns}$ & - \\
\hline \multirow[t]{2}{*}{$A 2 \mathrm{Hi}$} & $H$ & 17.5 & 23.3 & $0.70 \mathrm{~ns}$ \\
\hline & $D$ & 82.5 & 76.7 & \\
\hline \multirow[t]{3}{*}{$A 2 L o$} & $H$ & 53.9 & 30.5 & $15.42 * *$ \\
\hline & $D$ & 46.1 & 69.5 & \\
\hline & $\chi^{2}$ test & $22.46 * *$ & $1.20 \mathrm{~ns}$ & - \\
\hline \multirow[t]{2}{*}{$\mathrm{BR} \mathrm{Hi}$} & $H$ & 39.3 & 14.1 & $33.65 * *$ \\
\hline & $D$ & 60.7 & 85.9 & \\
\hline \multirow[t]{3}{*}{$B R L o$} & $H$ & 78.2 & 67.7 & $4.95 *$ \\
\hline & $D$ & 21.8 & 32.3 & \\
\hline & $\chi^{2}$ test & $39.78 * *$ & $87.80 * *$ & - \\
\hline
\end{tabular}

sion, the effect of the node position influence was very strong in the vigorous sprouts (high $\chi^{2}$ test values) where the most serious damage occurred most frequently in the lower region.

Relevant information is displayed in Fig. 11 and Fig. 12, which show the average

sprout features that distinguished the vigour classes: for each node along the axis, starting from the apex, the mean shoot length generated by each node is depicted separately for $H S, D S L$, and DSS. The figures show only $A 1$ and branches data, where the shoot frequency was higher. In the $A l$ graphs, the

Tab. 10 - Shoots damage susceptibility of high and low portions of the axes. (HS): healthy shoots; $(D S L)$ : shoots hanging gall only on the leaves; $(D S S)$ : deformed shoots. For each axis $(A 1, A 2, B R)$ mean values per sprout (\%) of healthy and damages shoots are reported. $\chi^{2}$ test results of the distribution of the healthy and damaged nodes between the vigour classes within the high or low axis portion and of the distribution of the healthy and damaged nodes between the high and low axis portion within the vigour classes. $(*): p<0.05 ;(* *): p<0.01$; $(* * *): \mathrm{p}<0.001 ;(\mathrm{ns})$ : not significant.

\begin{tabular}{|c|c|c|c|c|}
\hline Parameters & Vigour (\%) & NV & $\mathbf{V}$ & $\chi^{2}$ test \\
\hline \multirow[t]{3}{*}{$\mathrm{Al} \mathrm{Hi}$} & $H S$ & 34.9 & 43.2 & $8.33^{*}$ \\
\hline & $D S L$ & 22.1 & 31.8 & \\
\hline & $D S S$ & 43 & 25 & \\
\hline \multirow[t]{4}{*}{ Al Lo } & $H S$ & 53.8 & 3.8 & $27.08 * *$ \\
\hline & $D S L$ & 7.7 & 15.1 & \\
\hline & $D S S$ & 38.5 & 81.1 & \\
\hline & $\chi^{2}$ test & $4.13 \mathrm{~ns}$ & $53.37 * *$ & - \\
\hline \multirow[t]{3}{*}{$\mathrm{A2} \mathrm{Hi}$} & $H S$ & 12.3 & 18.5 & $1.98 \mathrm{~ns}$ \\
\hline & $D S L$ & 0 & 1.9 & \\
\hline & $D S S$ & 87.7 & 79.6 & \\
\hline \multirow[t]{4}{*}{$A 2 L o$} & $H S$ & 8.9 & 2.9 & $2.56 \mathrm{~ns}$ \\
\hline & $D S L$ & 0 & 0 & \\
\hline & $D S S$ & 91.1 & 97.1 & \\
\hline & $\chi^{2}$ test & $0.43 \mathrm{~ns}$ & $13.51^{* *}$ & - \\
\hline \multirow[t]{3}{*}{$\mathrm{BRHi}$} & $H S$ & 35.9 & 13.1 & $28.07 * *$ \\
\hline & $D S L$ & 21.4 & 32.5 & \\
\hline & $D S S$ & 42.7 & 54.4 & \\
\hline \multirow[t]{4}{*}{$B R L o$} & $H S$ & 22.9 & 8.5 & $5.29 \mathrm{~ns}$ \\
\hline & $D S L$ & 5.7 & 1.7 & \\
\hline & $D S S$ & 71.4 & 89.8 & \\
\hline & $\chi^{2}$ test & $9.35 * *$ & $28.58^{* *}$ & - \\
\hline
\end{tabular}

shoot emerging from the node number 1 (the highest bar in the graphs) is the future stem axis in the following growing season. In both vigour classes, for $A 1$ and for branches, the shoot length tended to decrease from the higher to the lower nodes. Differences were found among classes in relation to the damage position and shoot development. In vigorous sprouts, the first three top shoots were healthy or slightly damaged (only on the leaves), while the non-vigorous ones had serious damage from the top nodes. The deformed shoots on the branches occurred from the top nodes. Vigorous sprout shoot development was much higher according to the results of the length summation of nonattacked shoots. In terms of $A 1$ healthy shoots on vigorous sprouts, the total shoot length was $216 \mathrm{~cm}$, whereas for non-vigorous sprouts it was just $49 \mathrm{~cm}$. This huge difference increased if the length of shoots with hanging galls only on the leaves was added $(V=375 \mathrm{~cm}, N V=75)$. The same trend was observed on the branches: the vigorous healthy shoot length summation was $136 \mathrm{~cm}$ with $53 \mathrm{~cm}$ for the non-vigorous sprouts, while adding the damage to leaves meant the summations were $426 \mathrm{~cm}$ and $81 \mathrm{~cm}$, respectively.

\section{Discussion and Conclusions}

We performed a detailed damage classification to provide a more objective evaluation scheme for researchers and forest managers investigating gall wasp attacks of chestnut stands and orchards in terms of the reduced potential photosynthesis capacity of plants and their fruit and wood production. The literature is lacking in classification schemes and those available are either incomplete or unsuitable from a silvicultural viewpoint. Kato \& Hijii (1997) provided a simple classification that was based only on leaf damage types, which focused on leaf biomass and area reduction. Cooper \& Rieske (2009) described two types of galls in terms of their morphology and location on leaves or shoots. Sartor et al. (2009) developed a scheme to evaluate cultivar resistance, but it lacked sufficient detail in the description of shoot and leaf damage for our purposes, although this classification scheme was functional as a starting point. No publications make reference to stipule and dormant bud damage evaluations.

Thus, we described novel types of damage including galls on dormant buds and stipules. We also provided more detailed information on the morphology of the attacked shoots and leaves relative to their consequences for current plant growth and future development. This classification scheme highlights the impact of bud damage and different types of shoot damage. Bud and shoot damage directly effects the opportunity of producing new shoots and leaves. The data 
collected on 2009 galls that were still present on $A 2$ shoots allowed us to distinguish the damage types that caused organ death, thereby reducing the potential active photosynthesis area in subsequent growing seasons.

In order to provide a comprehensive $D$. kuriphilus damage classification scheme, we are currently conducting a study of galls on inflorescences in chestnut orchards.

It is essential to understand plant susceptibility in relation to vigour if we are to develop cultural practices that can reduce the impact of gall wasps. Moreover, the implementation of appropriate pruning methods requires the identification of the attack site, i.e., the plant axis that is more frequently attacked and the regions of axes that are most susceptible. We identified differences in susceptibility among plants and within plants. The published literature contains no data on susceptibility that is comparable to that presented here.

The most frequently attacked organs were shoots and the highest proportions of lethality were due to shoot damage ( $S 1$ and $S 2$ ). Including bud galls, the most serious, frequent damage was found in both stem axes and branches, which highlighted the negative effects of $D$. kuriphilus on future plant development and growth. Thus, a high frequency of regular and mostly healthy dormant buds provides a potential sink of healthy new organs that could become significantly infested. Excluding dormant bud damage, the three axes had different susceptibilities to gall wasp attack where the younger axis was the healthiest.

The results showing differences in the susceptibility of sprouts with varying levels of vigour must be carefully evaluated. Vigorous sprouts generally had a higher attack frequency on all the axes tested, especially $A 2$ and branches. However, these results must be evaluated relative to the development and growth of shoots, which could be healthy or damaged with no noticeable effects. Vigorous sprout nodes tend to produce for much longer, while less seriously damaged shoots reduced the negative effects on future plant development. In terms of the damage position, our results demonstrated a positive effect of the vigour state on the attack frequency in the upper axis portion. Vigorous sprouts also tended to be attacked less in the first nodes (starting from stem or branches apex). Deformed shoots were absent in the first three nodes and the most serious damage tended to be more frequent in the lower regions of $A 1$ and the branch axes. Thus, vigorous plants did not tend to lose their apex dominance, which controls stem growth. The maintenance of apex dominance is particularly important for qualitative aspects of wood production.

The healthier state of apical nodes, which

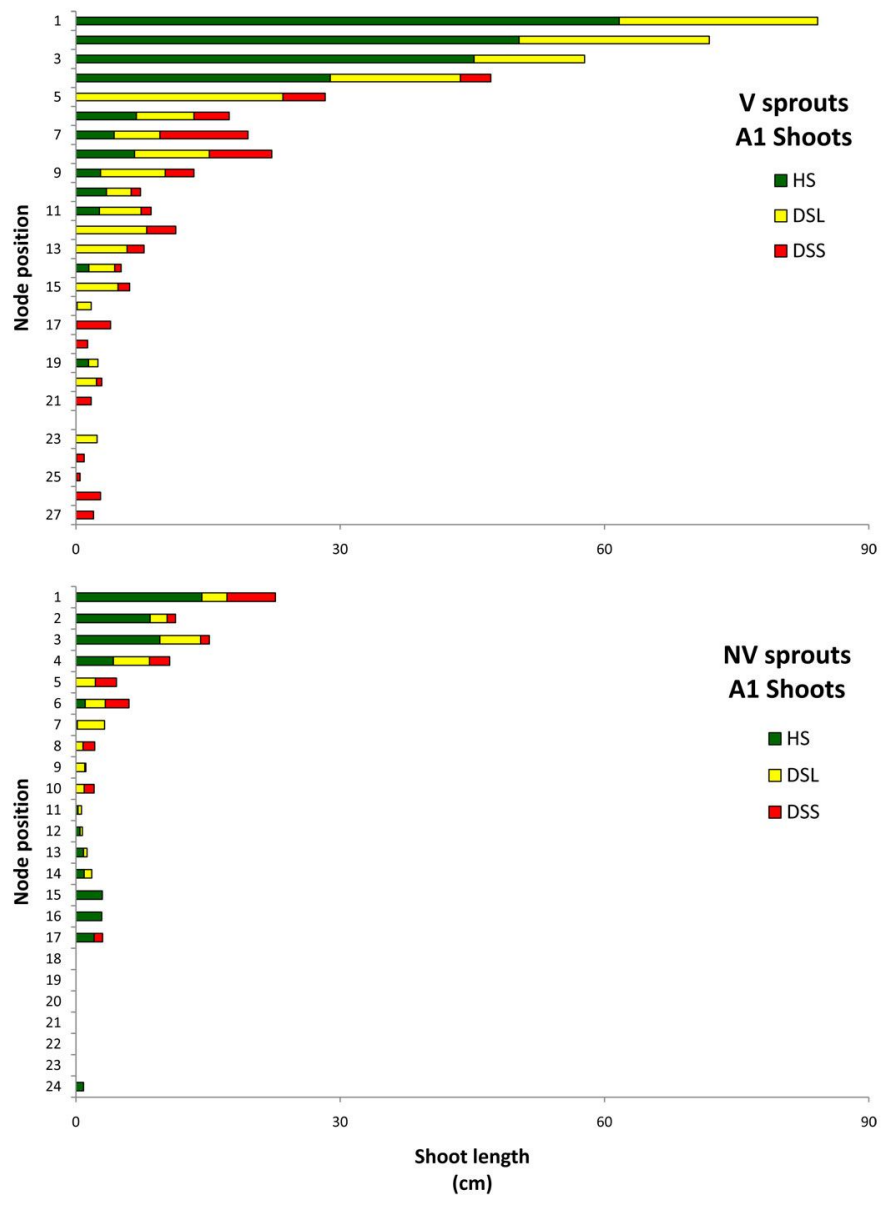

Fig. 11 - Mean length (per sprout) of the shoot developed by each single node in $A 1$, in relation to their phytosanitary state. Nodes are numbered starting from the apex (on the top: \#1) to the base. $(H S)$ : healthy shoots; (DSL): shoots hanging gall only on the leaves; (DSS).

deformed shoots; $(V)$ : vigourous sprouts; $(N V)$ : nonvigourous sprouts.

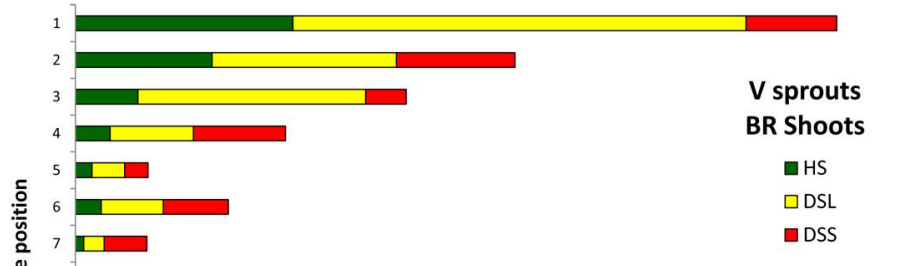

Fig. 12 - Mean length (per sprout) of the shoots developed by each node in all the branches in relation to shoot phytosanitary state. Nodes are numbered starting from the apex (on the top: \#1) to the base. $(H S)$ : healthy shoots; (DSL): shoots hanging gall only on the leaves; (DSS): deformed shoots; $(V)$ : vigourous sprouts; $(N V)$ : non vigourous sprouts.

NV sprouts BR Shoots

a HS

$\square D S L$

aDSS

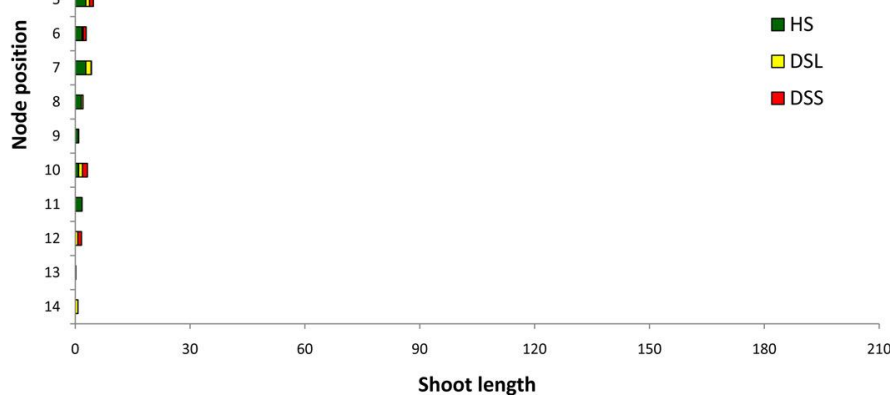


was mainly evident in vigorous sprouts, could be attributable to the period of bud formation and development. In vigorous plants, shoot growth continued for longer during the growing season and new apical buds could be formed at the end of July or later during the growing season. During the oviposition period (in Italy from mid-June to July - Salvadori et al. 2007), the apical bud would be in the first phase of its formation, thereby making it unsuitable for oviposition. New apical buds would develop when the adult insect has already completed its reproductive phase and it was no longer dangerous.

Information about the positive response of vigorous sprouts to gall wasp attack may help to explain why the insect is only lethal during severe plant vegetative weakness (Payne et al. 1975, Anagnotakis \& Payne 1993). Plant survival chances must be assessed relative to their good vegetative state in chestnut stands. Analyses of the attack distribution on vigorous sprouts (apical stem axis regions are basically healthy while shoot growth is prolonged during the summer season) are useful for developing appropriate cultural practices that could reduce the negative impact of gall wasps until effective biological control is implemented. Pruning and grafting practices should be modified to reduce plant susceptibility. Thus, we are testing a pruning method focused on developing new vegetative organs outside the period of adult gall wasp activity that consider the pruning timing (Maltoni et al. 2012).

\section{References}

Abe Y, Melika G, Stone GN (2007). The diversity and phylogeography of cynipid gallwasps $(H y$ menoptera, Cynipidae) of the Eastern Palearctic and their associated communities. Oriental insect 41: $169-212$

Aebi A, Schönrogge K, Melika G, Quacchia A, Alma A, Stone GN (2007). Native and introduced parasitoids attacking the invasive chestnut gall wasp Dryocosmus kuriphilus. Bulletin OEPP/EPPO Bulletin 37: 166-171. - doi 10.1111/j.1365-2338.2007.01099.x

Alma A, Ferrato V, Lessio F (2004). Lotta biologica al cinipide orientale del castagno mediante introduzione del parassitoide Torymus sinensis. Comunication in Convegno sul Cinipide galligeno del Castagno, 27 maggio 2004 Cuneo (Italia). [online] URL: http://www.provincia.cuneo.it/agricoltura/_allegati/cinipide_galligeno_castagno/presentazioni/alma.pdf

Anagnotakis SL, Payne JA (1993). Oriental chestnut gall wasp. Pest Alert NA-PR-02-93, USDA Forest Service, Northeastern Area, Ashville, NC, USA.

Bosio G, Gerbaudo C, Piazza E (2010). Dryocosmus kuriphilus Yasumatsu: an outline seven years after the first report in Piedmont (Italy). In: Proceedings of I European Congress on Chestnut “Castanea 2009”. Acta Horticulturae 866: 341-
348.

Botta R, Mellano MG, Beccaro GL, Bounous G, Alma A, Quacchia A, Bosio G, Picciau L (2005). Cinipide galligeno del castagno: primi risultati di lotta biologica e di valutazione della sensibilità varietale. In: "Atti del IV Convegno Nazionale Castagno 2005". Montella (AV - Italy) 20-22 October 2005.

Cooper WR, Rieske LK (2007). Community associates of an exotic Gallmaker, Dryocosmus kuriphilus (Hymenoptera: Cynipidae), in Eastern North America. Annals of the Entomological Society of America 100 (2): 236-244. - doi: 10.1603/0013-8746(2007)100[236:CAOAEG]2. $0 . \mathrm{CO} ; 2$

Cooper WR, Rieske LK (2009). Woody stem galls interact with foliage to affect community associations. Environmental Entomology 38 (2): 417-424. - doi: 10.1603/022.038.0215

EFSA (2010). Risk assessment of the oriental chestnut gall wasp, Dryocosmus kuriphilus for the EU territory and identification and evaluation of risk management options. EFSA Journal 8 (6): 1619 [online] URL: http://www.efsa.europa.eu/ en/efsajournal/pub/1619.htm

EPPO (2006). First record of Dryocosmus kuriphilus in Slovenia. EPPO Reporting Service 5: 2006/101. [online] URL: http://archives.eppo. org/EPPOReporting/2006/Rse-0605.pdf

EPPO (2007). Dryocosmus kuriphilus found in South France (Alps maritimes). EPPO Reporting Service 5: 2008/086.

EPPO (2008). Situation of Dryocosmus kuriphilus in France. EPPO Reporting Service 5, 2008/097.

Forster B, Engesser R, Meier F (2009). Situazione fitosanitaria attuale - 2/2009. [online] URL: http://www.waldschutz.ch

Graziosi I, Santi F (2008). Chestnut gall wasp (Dryocosmus kuriphilus): spreading in Italy and new records in Bologna province. Bulletin of Insectology 61 (2): 343-348. [online] URL: http://www.bulletinofinsectology.org/pdfarticles/ vol61-2008-343-348graziosi.pdf

Kajiura M, Machida Y (1961). The breeding of resistant varieties to some insects and diseases in fruit trees. Japanese Journal of Breeding 11: 137140.

Kato K, Hijii N (1997). Effects of gall formation by Dryocosmus kuriphilus Yasumatsu (Hym, Cynipidae) on the growth of chestnut trees. Journal of Applied Entomology 121: 9-15. - doi: 10.1111/j.1439-0418.1997.tb01363.x

Maltoni A, Mariotti B, Tani A (2010). Il cinipide del castagno. Diffusione e riflessioni su alcune pratiche colturali. Sherwood 165: 21-24.

Maltoni A, Mariotti B, Jacobs DF, Tani A (2012). Pruning methods to restore Castanea sativa stands attacked by Dryocosmus kuriphilus. New Forests (Special Issue: Restoring Forests) [in press] - doi: 10.1007/s11056-012-9323-y

Mariotti B, Maltoni A, Maresi G (2009). Tradizione, innovazione e sostenibilità: una selvicoltura per il castagno da frutto. In: "Atti del Terzo Congresso Nazionale di Selvicoltura: per il miglioramento e la conservazione dei boschi italiani" (Ciancio ed). Accademia Italiana di Scienze Forestali pp. 851-857. [online] URL: http://www.aisf.it/AttiCNS/pdf/volume $\% 202 / 2.43 \% 20$ Mariotti.pdf

MiPAF (2010a). Piano del Settore Castanicolo 2010-2013. 1. Documento di sintesi del 18 novembre 2010. Ministero delle Politiche Agricole e Forestali. [online] URL: http://www. politicheagricole.it/SettoriAgroalimentari/Castan icolo/default.htm

MiPAF (2010b). Piano del Settore Castanicolo 2010-2013. 2. Riferimenti di tecniche di lotta biologica con Torymus sinensis. Ministero delle Politiche Agricole e Forestali. [online] URL: http://www.politicheagricole.it/SettoriAgroalimentari/Castanicolo/default.htm

MiPAF (2010c). Piano del Settore Castanicolo 2010-2013. 3. Elaborato dei gruppi di lavoro del settore castanicolo. Ministero delle Politiche Agricole e Forestali. [online] URL: http://www.politicheagricole.it/SettoriAgroalimentari/Castan icolo/default.htm

MiPAF (2010d). Piano del Settore Castanicolo 2010-2013. 4. Elaborato delle Regioni sulla castanicoltura territoriale. Ministero delle Politiche Agricole e Forestali. [online] URL: http://www.politicheagricole.it/SettoriAgroalimentari/Castanicolo/default.htm

Moriya S, Inoue K, Otake A, Shiga M, Mabuchi M (1989). Decline of the chestnut gall wasp population, Dryocosmus kuriphilus Yasumatsu ( $\mathrm{Hy}$ menoptera: Cynipidae) after the establishment of Torymus sinensis Kamijo (Hymenoptera: Torymidae). Journal of Applied Entomology and Zoology 24 (2): 231-233.

Moriya S, Shiga M, Adachi I (2002). Classical biological control of the chestnut gall wasp in Japan. In: Proceedings of the "First international symposium on biological control of arthropods" (van Driesche ed). Honolulu (Hawaii - USA) 1418 January 2002. USDA Forest Service, Washington, USA, pp. 407-415.

Moriya S, Adachi I, Shiga M (2004). Biological control of chestnut gall wasp in Japan. In: Proceedings of the "Convegno sul Cinipide galligeno del Castagno". Cuneo (Italy) 27 May 2004. [online] URL: http://www.provincia.cuneo.it/agricoltura/_allegati/cinipide_galligeno_castagno/p resentazioni/moriya.pdf

Murakami Y (1981). Comparison of the adult emergence periods between Torymus (Syntomaspis) beneficus a native parasitoid of the chestnut gall wasp and a congeneric parasitoid imported from China (Hymenoptera: Torymidae). In: Proceedings of the Association for Plant Protection of Kyushu 27: 156-158. - doi: 10.4241/kyubyochu. 27.156

Murakami Y, Toda S, Gyoutoku Y (2001). Colonization of imported Torymus (Syntomaspis) sinensis Kamijo (Hymenoptera: Torymidae) parasitic on the chestnut gall wasp (Hymenoptera: Cynipidae). Success in the eighteenth year after release in Kunamoto. In: Proceedings of the Association for Plant Protection of Kyushu 47: 132134. - doi: 10.4241/kyubyochu.47.132

Payne JA, Menke AS, Schroeder PM (1975). 
Dryocosmus kuriphilus Yasumatsu (Hymenoptera: Cynipidae), an oriental chestnut gall wasp in North America. Cooperative Economic Insect Report 25 (49-52): 903-905.

Quacchia A, Moryia S, Bosio G, Scapin I, Alma A (2008). Rearing, release and the prospect of establishment of Torymus sinensis, biological control agent of the chestnut gall wasp Dryocosmus kuriphilus, in Italy. BioControl 53 (6): 829-839. - doi: 10.1007/s10526-007-9139-4

Regione Toscana (2002). Progetto carta dei suoli in scala 1:250.000. [online] URL: http://www.sit.lamma.rete.toscana.it/websuoli/

Salvadori C, Maresi G, Tessari L (2007). Il cinipide galligeno del castagno Terra trentina 53 (9)
24-29.

Sartor C, Botta R, Mellano MG, Beccaro GL, Bounous G, Torello Marinoni D, Quacchia A, Alma A (2009). Evaluation of susceptibility to Dryocosmus kuriphilus Yasumatsu (Hymenoptera: Cynipidae) in Castanea sativa Miller and in hybrid cultivars. In: Proceedings of "International Workshop on Chestnut Management in Mediterranean Countries - Problems and Prospects" (Soylu, Mert eds). Bursa (Turkey). Acta Horticolturae 815: 289-294.

Shimura I (1972). Studies on the breeding of chestnut, Castanea spp. II. Parasitic variation in the chestnut gall wasp, Dryocosmus kuriphilus Yasumatsu. Bullettin of the Horticultural Re- search Station, Ser. A 11, pp. 13. [In Japanese with English summary].

Tani A, Maltoni A, Maresi G, Mariotti B (2010). Riflessioni sull'effetto di pratiche colturali in castagneti con presenza di Dryocosmus kuriphilus. In: Proceedings of the " 5 " Congresso Nazionale Castagno - Castanea 2009”. Cuneo (Italy) 13-16 October 2009, pp. 75-82.

Turchetti T, Addario E, Maresi G (2010). Interazioni tra cinipide galligeno e cancro della corteccia: una nuova criticità per il castagno. Forest@ 7: 252-258. - doi: 10.3832/efor0642007 